\title{
recildunds
}

Revista Cientifica Mundo de la Investigación y el Conocimiento

Javier Enrique Ponce Rodríguez a; Martha Alexandra García Montiel ${ }^{\text {b }}$; Nathalie María Barriga Reyes ${ }^{c}$; Barbara Pauleth Quiroz Zurita ${ }^{\mathrm{d}}$

Morbimortalidad producida por enfermedad diarreica

Morbimortality produced by diarrheal disease

Revista Científica Mundo de la Investigación y el Conocimiento. Vol. 3 núm. 4., diciembre, ISSN: 2588-073X, 2019, pp. 212-232

DOI: $10.26820 /$ recimundo/3.(4).diciembre.2019.212-232

URL: http://recimundo.com/index.php/es/article/view/660

Código UNESCO: 3205 Medicina Interna

Tipo de Investigación: Artículo de Revisión

(C) RECIMUNDO; Editorial Saberes del Conocimiento, 2019

Recibido: 15/09/2019

Aceptado: 23/11/2019

Publicado: 30/12/2019

Correspondencia: javo89_18@hotmail.com

a. Médico; Investigador Independiente; Guayaquil, Ecuador; javo89_18@ @otmail.com

b. Médico; Investigador Independiente; Guayaquil, Ecuador; maralex22@ hotmail.com

c. Médico; Investigador Independiente; Guayaquil, Ecuador; nathyb_24@ hotmail.com

d. Médico; Investigador Independiente; Guayaquil, Ecuador; barbara.2208@ hotmail.com 


\section{Morbimortalidad producida por enfermedad diarreica}

Vol. 3, núm. 4., (2019)

Jessica Karina Borja Arias; Karol Natalie Galarza Ávila; Luis Javier Álvarez Moyon; Andrea del

Consuelo Torres Guzmán

\section{RESUMEN}

Las enfermedades diarreicas constituyen un problema de salud pública en el mundo. En apoyo a esto, se describe el Informe del Fondo de las Naciones Unidas (UNICEF, 2017), titulado refiere:: “cada año mueren en el mundo más de 3,5 millones de niños y personas como consecuencia de diarrea". Entiéndase con esto que, la diarrea aguda constituye un gran problema de salud pública. Se estima además que el $70 \%$ de las diarreas se originan por la ingestión de alimentos contaminados con microbios y sus toxinas, en cantidades suficientes para afectar la salud del consumidor, por lo que se reconocen como enfermedades transmitidas por alimentos, lo que generalmente se debe a la influencia de determinados factores de riesgo, entre los que se destacan la malnutrición por defecto, factores ambientales, inmunodeficiencia celular, destete precoz y otros. Dicho de esta forma, la diarrea significa un inminente problema de salud pública; el mismo, ha sido reconocido a nivel mundial resaltándose que: entre sus factores se encuentren: las condiciones geográficas, sociales, culturales y servicios públicos; lo que ha llevado a que la misma constituya una de las consultas más frecuentes en los servicios de consulta externa, urgencias y consultorios de médicos generales y pediatras. Por ende, la diarrea es una enfermedad gastrointestinal que se manifiesta con deposiciones, de tres o más veces al día de heces sueltas o líquidas. La deposición frecuente de heces formes (de consistencia sólida) no es diarrea, ni tampoco la deposición de heces de consistencia suelta y "pastosa" por bebés amamantados. Esta patología suele ser un síntoma de una infección del tracto digestivo, que puede estar ocasionada por diversos organismos bacterianos, víricos y parásitos; de allí que sea transmitida, a través de alimentos o agua de consumo contaminado, o bien de una persona a otra como resultado de una higiene deficiente.

Palabras Claves: Morbimortalidad; Enfermedad Diarreica; Organismos Bacterianos; Factores de Riesgo; Malnutrición. 


\section{Morbimortalidad producida por enfermedad diarreica}

Vol. 3, núm. 4., (2019)

Jessica Karina Borja Arias; Karol Natalie Galarza Ávila; Luis Javier Álvarez Moyon; Andrea del Consuelo Torres Guzmán

\section{ABSTRACT}

Diarrheal diseases constitute a public health problem in the world. In support of this, the United Nations Fund Report (UNICEF, 2017) is described, entitled: "more than 3.5 million children and people die each year as a result of diarrhea". Understand with this that, acute diarrhea is a major public health problem. It is also estimated that $70 \%$ of diarrhea originates from the ingestion of food contaminated with microbes and their toxins, in sufficient quantities to affect the health of the consumer, which is why they are recognized as foodborne diseases, which is generally due to the influence of certain risk factors, among which malnutrition by default, environmental factors, cellular immunodeficiency, early weaning and others stand out. Said in this way, diarrhea means an imminent public health problem; it has been recognized worldwide, highlighting that: its factors include: geographical, social, cultural and public services conditions; which has led to it being one of the most frequent consultations in the outpatient services, emergency and general practitioners and pediatricians' offices. Therefore, diarrhea is a gastrointestinal disease that manifests with bowel movements, three or more times a day of loose or liquid stools. Frequent stool deposition (of solid consistency) is not diarrhea, nor is stool deposition of loose and "pasty" consistency by breastfed babies. This pathology is usually a symptom of a digestive tract infection, which may be caused by various bacterial, viral and parasitic organisms; hence it is transmitted, through contaminated food or drinking water, or from one person to another as a result of poor hygiene.

Keywords: Morbidity and mortality; Diarrheal Disease; Bacterial Organisms; Risk Factors; Malnutrition. 


\section{Morbimortalidad producida por enfermedad diarreica}

Vol. 3, núm. 4., (2019)

Jessica Karina Borja Arias; Karol Natalie Galarza Ávila; Luis Javier Álvarez Moyon; Andrea del

Consuelo Torres Guzmán

\section{Introducción.}

A través de la historia de la humanidad, los pueblos han buscado mantener, proteger y recuperar su salud: para ello, los gobiernos han organizado diferentes políticas con el fin de optimizar los recursos humanos, físicos, económicos y ambientales, partiendo de enfoques y estrategias variadas de acuerdo al momento y situación social que se esté viviendo. (Mota, 2016). He aquí, la importancia de los programas de salud comunitarios establecidos por los gobiernos y las diferentes organizaciones, los cuales buscan concientizar a los habitantes de las diferentes poblaciones sobre las causas y efectos que tienen determinadas patologías médicas con el fin de promocionar la salud.

A tal efecto, hablar de programas y medidas de prevención y promoción de la salud, es hacer referencia al conjunto de estrategias médico - comunitarias dirigidas hacia el fomento de estilos de vida saludables, los cuales orientan sus esfuerzos, tanto a la población en general, como a los individuos en el contexto de su vida cotidiana; buscando con ello, actuar en lo colectivo sobre los determinantes de la salud, promoviendo las normas de auto cuidado a seguir y las previsiones médicas necesarias, a fin de alcanzar el bienestar tanto de la persona sana como de la enferma. (Ortiz, 2017).

De aquí, que la puesta en práctica de planes de prevención médica representan una medida social, la cual permite a las personas y comunidades en general minimizar los riesgos de sufrir de las enfermedades de más alta prevalencia, disminuyendo así, el nivel de los factores de riesgo o de la probabilidad de su ocurrencia. (Ortiz, 2017). Lo descrito, lleva a considerar la importancia social que tienen los planes de intervención médicos comunitarios, ya que los 


\section{Morbimortalidad producida por enfermedad diarreica}

Vol. 3, núm. 4., (2019)

Jessica Karina Borja Arias; Karol Natalie Galarza Ávila; Luis Javier Álvarez Moyon; Andrea del Consuelo Torres Guzmán

mismos se basan en el desarrollo integral de la salud incorporando para ello, programas nacionales apropiados para cada situación o patología a tratarse.

En tal sentido, es importante entender que entre los propósitos que encierran estos programas o medidas médicas de prevención, se encuentra influir en el estilo de vida de los ciudadanos, con el fin de minimizar las enfermedades de alta prevalencia; obsérvese como ejemplo el caso de las diarreas agudas, las cuales son responsables de una morbimortalidad considerable en el mundo entero; las mismas se presentan frecuentemente con síntomas no específicos y altas tasas de prevalencia). (Ortiz, 2017)

Lo anteriormente expuesto, permite resaltar lo observado en países latinoamericanos en donde la diarrea aguda se ha convertido en una enfermedad que hay que atacar, ya que su prevalencia depende en gran medida de los hábitos higiénicos de la población, y se encuentra relacionada con conductas socioeconómicas y culturales; problemática ésta que, lleva a considerar la necesidad de ejecutar planes de intervención comunitarios, los cuales les permitan a las comunidades tomar las previsiones médicas necesarias para disminuir los riesgos de contagios de este tipo de patología; pues la misma es originada, en muchos de los casos por ingestión de alimentos contaminados, inadecuados hábitos higiénicos, condiciones ambientales inapropiadas, bajo nivel socio - económico, entre otras tantas causantes. (Ortiz, 2017).

En la misma línea de ideas, se debe expresar que la diarrea aguda es una enfermedad que afecta a todas las personas por igual, sin embargo la población infantil por sus características poseen un nivel de susceptibilidad elevado de padecerlas, ya que existe mayor oportunidad de contacto con dichos parásitos porque permanecen gran parte del día en las escuelas y desarrollan 


\section{Morbimortalidad producida por enfermedad diarreica}

Vol. 3, núm. 4., (2019)

Jessica Karina Borja Arias; Karol Natalie Galarza Ávila; Luis Javier Álvarez Moyon; Andrea del Consuelo Torres Guzmán

actividades en colectivo, lo que puede favorecer las condiciones para la transmisión de algunas enfermedades parasitarias, especialmente aquellas en que su principal mecanismo de transmisión es la vía fecal oral, además de presentar un menor nivel inmunológico. (Ortiz, 2017)

En en otras palabras, se puede decir que este tipo de afección representa una de las enfermedades más frecuentes en la comunidad y en el ámbito escolar, por lo que es recomendable desarrollar planes de intervención médica, los cuales le permitan a padres y representantes orientar sobre las medidas médicas a seguir para su debida prevención. (Ortiz, 2017). Es por tal razón que, la puesta en práctica de planes de intervención médicas, se convierte en estas comunidades en la mejor herramienta del personal de salud, ya que para lograr cambiar las conductas de riesgo, primero se necesita mejorar el nivel de información de las poblaciones.

Lo señalado anteriormente, lleva a comprender que los planes de intervención médico comunitarios le permiten a los individuos cuidar de su salud como complemento del compromiso estatal y de la importancia que tiene, para el concepto integral de salubridad de una Nación. He allí, la importancia de aquellos programas dirigidos a concientizar sobre las medidas médico sanitarias a seguirse para prevenir la diarrea aguda. (Ortiz, 2017)

Lo antes expuesto, conduce a entender la importancia que tiene el comportamiento humano en la transmisión de las infecciones intestinales por parásitos en el padecimiento de diarreas agudas, por lo tanto el éxito de las medidas de control que se implementen dependerá en gran medida de la modificación que se obtenga de los hábitos en el sentido de promover la salud y no contribuir a deteriorarla. (Ortiz, 2017). No obstante, se observa con preocupación que en países latinoamericanos la morbimortalidad de casos producida por diarreas agudas puede estar 


\section{Morbimortalidad producida por enfermedad diarreica}

Vol. 3, núm. 4., (2019)

Jessica Karina Borja Arias; Karol Natalie Galarza Ávila; Luis Javier Álvarez Moyon; Andrea del Consuelo Torres Guzmán

determinado por diferentes causas, incluyéndose entre ellas, a una escasa formación socio cultural, bajo nivel socio económico, deficiente información sobre las medidas higiénico sanitarias a seguirse para la prevención de determinadas afecciones médicas, indicadores éstos que llevan a considerar la presencia de una problemática de salud.

\section{Fuentes documentales}

El análisis correspondiente a las características que predomina en el tema seleccionado, llevan a incluir diferentes fuentes documentales encargadas de darle el respectivo apoyo y en ese sentido cumplir con la valoración de los hechos a fin de generar nuevos criterios que sirven de referencia a otros procesos investigativos. Para (Arias, 2010), las fuentes documentales incorporadas en la investigación documental o bibliográfica, "representa la suma de materiales sistemáticos que son revisados en forma rigurosa y profunda para llegar a un análisis del fenómeno". (p.41). Por lo tanto, se procedió a cumplir con la realización de una lectura previa determinada por encontrar aquellos aspectos estrechamente vinculados con la "MORBIMORTALIDAD PRODUCIDA POR ENFERMEDAD DIARREICA para luego explicar mediante un desarrollo las respectivas apreciaciones generales de importancia.

\section{Técnicas para la Recolección de la Información}

La conducción de la investigación para ser realizada en función a las particularidades que determinan a los estudios documentales, tiene como fin el desarrollo de un conjunto de acciones encargadas de llevar a la selección de técnicas estrechamente vinculadas con las características del estudio. En tal sentido, (Arias Ob cit) refiere, que es "una técnica particular para aportar ayuda a los procedimientos de selección de las ideas primarias y secundarias”. (p. 71). 


\section{Morbimortalidad producida por enfermedad diarreica}

Vol. 3, núm. 4., (2019)

Jessica Karina Borja Arias; Karol Natalie Galarza Ávila; Luis Javier Álvarez Moyon; Andrea del Consuelo Torres Guzmán

Por ello, se procedió a la utilización del subrayado, resúmenes, fichaje, como parte básica para la revisión y selección de los documentos que presentan el contenido teórico. Es decir, que mediante su aplicación de estas técnicas se pudo llegar a recoger informaciones en cuanto a la revisión bibliográfica de los diversos elementos encargados de orientar el proceso de investigación. Tal como lo expresa, (Arias Ob cit) "las técnicas documentales proporcionan las herramientas esenciales y determinantes para responder a los objetivos formulados y llegar a resultados efectivos" (p. 58). Es decir, para responder con eficiencia a las necesidades investigativas, se introdujeron como técnica de recolección el método inductivo, que hizo posible llevar a cabo una valoración de los hechos de forma particular para llegar a la explicación desde una visión general.

Asimismo, se emplearon las técnicas de análisis de información para la realización de la investigación que fue ejecutada bajo la dinámica de aplicar diversos elementos encargados de determinar el camino a recorrer por el estudio, según, (Arias, Ob cit) las técnicas de procesamiento de datos en los estudios documentales "son las encargadas de ofrecer al investigador la visión o pasos que debe cumplir durante su ejercicio, cada una de ellas debe estar en correspondencia con el nivel a emplear" (p. 123). Esto indica, que para llevar a cabo el procesamiento de los datos obtenidos, es necesario establecer las técnicas que serán seleccionadas, destacándose en este caso, de manera particular: fichas de resumen, textual, registros descriptivos entre otros, los mismos se deben ajustar al nivel que ha sido seleccionado. 


\section{Morbimortalidad producida por enfermedad diarreica}

Vol. 3, núm. 4., (2019)

Jessica Karina Borja Arias; Karol Natalie Galarza Ávila; Luis Javier Álvarez Moyon; Andrea del Consuelo Torres Guzmán

\section{Resultados.}

\section{Enfermedad Diarreica}

La diarrea es un signo que revela una alteración fisiopatológica de una o varias funciones del intestino (secreción, digestión, absorción o motilidad) y que en último término indica un trastorno del transporte intestinal de agua y electrolitos. Asimismo, se establece que esta patología representa un mecanismo de respuesta por parte del organismo frente a un agente agresor, por lo que puede derivar de una diarrea infecciosa, cuando es causada por enteropatógenos como bacterias, virus, hongos, parásitos y no infecciosa, inflamatoria, endocrina, tumoral, medicamentosa o por mal absorción. (Pereira, 2016)

En acompañamiento de esto, la Organización Mundial de la Salud (OMS 2017), define la diarrea como "a expulsión de tres o más evacuaciones liquidas con o sin sangre en 24 horas, y episodios diarreicos, en todo caso, se entiende como diarrea persistente aquel episodio diarreico de más de 14 días de duración, de comienzo agudo y presunta etiología infecciosa, que afecta el estado nutricional y pone al paciente en riesgo sustancial de muerte. (Pereira, 2016). He aquí, que algunos lactantes pueden presentar diarrea intratable grave debida fundamentalmente a defectos congénitos de la digestión y absorción o una ineficaz maduración del sistema inmune intestinal.

Las causas no infecciosas de la diarrea están dadas por una dieta inadecuada (la ingestión de grandes cantidades de alimentos, las fórmulas de leche muy concentradas, etc.), por medicamentos (preparados de hierro, antibióticos), sustancias que actúan como laxantes, por alergias transitorias a las proteínas de la dieta, contaminación del agua por agentes químicos 


\section{Morbimortalidad producida por enfermedad diarreica}

Vol. 3, núm. 4., (2019)

Jessica Karina Borja Arias; Karol Natalie Galarza Ávila; Luis Javier Álvarez Moyon; Andrea del Consuelo Torres Guzmán

(arsénico, plomo, mercurio entre otras) o por enfermedades endocrino metabólicas. (Pereira, 2016)

El diagnóstico etiológico de las diarreas agudas es complejo; esto, debido a que sus causas, especialmente en niños y ancianos pueden ser diversas, siendo la principal de ellas los agentes infecciosos, y posteriormente el aislamiento de enteropatógenos, encontrándose entre ellos, principalmente bacterias en $42 \%$ - $50 \%$, rotavirus $24,1 \%$ y parásitos $6,5 \%$; todos estos transmitidos por causas diversas. (Kassem, 2016). De allí que la valoración que realiza el profesional de la salud en la atención que se brinda a los niños con diarrea aguda, cumple un papel fundamental en su recuperación, ya que del mismo depende la recogida sistemática y organizada de todos los datos subjetivos y objetivos que permitan de una manera coordinada y racional identificar los factores predisponentes que conlleven a establecer su debida prevención.

Por ende, se establece que la etiología de la diarrea aguda infecciosa, incluye bacterias, parásitos y virus, la misma varía según la edad y el área geográfica; de allí, que se estima que el 90\% de las gastroenteritis en niños menores de 3 años son de etiología viral, entre estos los virus más frecuentemente implicados son Rotavirus, Adenovirus, Norovirus, Astrovirus y Sapovirus; señálese también que los Adenovirus representan el segundo agente causal de gastroenteritis agudas después del Rotavirus, y constituye entre el 5 - 20\% de los casos de diarrea en niños hospitalizados. (Kassem, 2016).

Se puede decir entonces que existe un número considerable de elementos infecciosos que conducen a cuadros diarreicos agudos, lo que lleva a considerar la importancia que tiene el comportamiento humano en la transmisión de las infecciones intestinales por parásitos, por lo 


\section{Morbimortalidad producida por enfermedad diarreica}

Vol. 3, núm. 4., (2019)

Jessica Karina Borja Arias; Karol Natalie Galarza Ávila; Luis Javier Álvarez Moyon; Andrea del Consuelo Torres Guzmán

tanto el éxito de las medidas de control que se implementen dependerá en gran medida de la modificación que se obtenga de los hábitos asumidos por las poblaciones en el sentido de promover la salud y no contribuir a deteriorarla. (Kassem, 2016).

\section{Morbimortalidad producida por Diarrea}

Las enfermedades diarreicas son una causa principal de mortalidad y morbilidad en la niñez y en personas adultas (mayormente adultos mayores) en el mundo, y por lo general son consecuencia de la exposición a alimentos o agua contaminados. En todo el mundo, 780 millones de personas carecen de acceso al agua potable, y 2500 millones a sistemas de saneamiento apropiados. La diarrea causada por infecciones es frecuente en países en desarrollo. En países de ingresos bajos, los niños menores de tres años sufren, de promedio, tres episodios de diarrea al año. Cada episodio priva a la persona o niño de nutrientes necesarios para su crecimiento. En consecuencia, la diarrea es una importante causa de malnutrición, y los niños malnutridos son más propensos a enfermar por enfermedades diarreicas. (Kassem, 2016).

\section{Deshidratación}

La amenaza más grave de las enfermedades diarreicas es la deshidratación. Durante un episodio de diarrea, se pierde agua y electrolitos (sodio, cloruro, potasio y bicarbonato) en las heces líquidas, los vómitos, el sudor, la orina y la respiración. Cuando estas pérdidas no se restituyen, se produce deshidratación. El grado de deshidratación se mide en una escala de tres:

Deshidratación grave (al menos dos de los signos siguientes):

- letargo o pérdida de conocimiento; 


\section{Morbimortalidad producida por enfermedad diarreica}

Vol. 3, núm. 4., (2019)

Jessica Karina Borja Arias; Karol Natalie Galarza Ávila; Luis Javier Álvarez Moyon; Andrea del Consuelo Torres Guzmán

- ojos hundidos;

- $\quad$ no bebe o bebe poco;

- retorno lento (2 segundos o más) a la normalidad después de pellizcar la piel.

Deshidratación moderada (al menos dos de los signos siguientes):

- desasosiego o irritabilidad;

- ojos hundidos;

- bebe con ganas, tiene sed.

Ausencia de deshidratación (no hay signos suficientes para diagnosticar una deshidratación grave o moderada).

\section{Causas}

Infección: la diarrea es un síntoma de infecciones ocasionadas por muy diversos organismos bacterianos, víricos y parásitos, la mayoría de los cuales se transmiten por agua con contaminación fecal. La infección es más común cuando hay escasez de agua limpia para beber, cocinar y lavar. Las dos causas más frecuentes de diarrea moderada a grave en países de ingresos bajos son los rotavirus y Escherichia coli. Otros patógenos, como Cryptosporidium y Shigella, también pueden ser importantes. Asimismo, es necesario tener en cuenta etiologías específicas de cada lugar.

Malnutrición: los niños que mueren por diarrea suelen padecer malnutrición subyacente, lo que les hace más vulnerables a las enfermedades diarreicas. A su vez, cada episodio de diarrea 


\section{Morbimortalidad producida por enfermedad diarreica}

Vol. 3, núm. 4., (2019)

Jessica Karina Borja Arias; Karol Natalie Galarza Ávila; Luis Javier Álvarez Moyon; Andrea del Consuelo Torres Guzmán

empeora su estado nutricional. La diarrea es la segunda mayor causa de malnutrición en niños menores de cinco años.

Fuente de agua: el agua contaminada con heces humanas procedentes, por ejemplo, de aguas residuales, fosas sépticas o letrinas, es particularmente peligrosa. Las heces de animales también contienen microorganismos capaces de ocasionar enfermedades diarreicas.

Otras causas: las enfermedades diarreicas pueden también transmitirse de persona a persona, en particular en condiciones de higiene personal deficiente. Los alimentos elaborados o almacenados en condiciones antihigiénicas son otra causa principal de diarrea. El almacenamiento y manipulación del agua doméstica en condiciones carentes de seguridad también es un factor de riesgo importante. Asimismo, pueden ocasionar enfermedades diarreicas el pescado y marisco de aguas contaminadas.

\section{Prevención y Tratamiento}

Entre las medidas clave para prevenir las enfermedades diarreicas cabe citar las siguientes:

- el acceso a fuentes inocuas de agua de consumo;

- uso de servicios de saneamiento mejorados;

- lavado de manos con jabón;

- lactancia exclusivamente materna durante los primeros seis meses de vida;

- una higiene personal y alimentaria correctas;

- la educación sobre salud y sobre los modos de transmisión de las infecciones; 


\section{Morbimortalidad producida por enfermedad diarreica}

Vol. 3, núm. 4., (2019)

Jessica Karina Borja Arias; Karol Natalie Galarza Ávila; Luis Javier Álvarez Moyon; Andrea del Consuelo Torres Guzmán

- la vacunación contra rotavirus.

Entre las medidas clave para tratar las enfermedades diarreicas cabe citar las siguientes:

- Rehidratación: con solución salina de rehidratación oral (SRO). Las SRO son una mezcla de agua limpia, sal y azúcar. Cada tratamiento cuesta unos pocos céntimos. Las SRO se absorben en el intestino delgado y reponen el agua y los electrolitos perdidos en las heces.

- Complementos de zinc: los complementos de zinc reducen un 25\% la duración de los episodios de diarrea y se asocian con una reducción del 30\% del volumen de las heces.

- Rehidratación con fluidos intravenosos en caso de deshidratación severa o estado de choque.

- Alimentos ricos en nutrientes: el círculo vicioso de la malnutrición y las enfermedades diarreicas puede romperse continuando la administración de alimentos nutritivos incluida la leche materna - durante los episodios de diarrea, y proporcionando una alimentación nutritiva —incluida la alimentación exclusiva con leche materna durante los seis primeros meses de vida— a los niños cuando están sanos.

- Consulta a un agente de salud, en particular para el tratamiento de la diarrea persistente o cuando hay sangre en las heces o signos de deshidratación.

De manera general, se debe referir que las diarreas agudas, representan una de las patologías más frecuentes en las consultas de Atención Primaria. En los últimos años, se están produciendo cambios, tanto en su incidencia como en su etiología, debido al aumento de la población en zonas que no cuentan con los servicios básicos de salubridad y a la escasa cultura 


\section{Morbimortalidad producida por enfermedad diarreica}

Vol. 3, núm. 4., (2019)

Jessica Karina Borja Arias; Karol Natalie Galarza Ávila; Luis Javier Álvarez Moyon; Andrea del Consuelo Torres Guzmán

educativa sobre lo que este tipo de afección intestinal respecta, llevando a que la misma sea considerada un problema de salud pública, el cual afecta a individuos de todas las edades y sexos; pero se presentan sobre todo en los primeros años de vida; especialmente en niños lactantes, ya que este grupo de edad aún no ha adquirido los hábitos higiénicos necesarios para prevenirlas siendo los mismos indefensos y dependientes del cuido que hacen de ellos sus representantes. (Kassem, 2016).

Esta patología de orden infecciosa es ocasionada por bacterias y la calidad del agua, la carencia de servicios de agua y desagüe, la falta de adecuados hábitos de higiene. Asimismo, el lavado de manos con jabón juega un rol importante en la reducción de la morbimortalidad infantil vinculada a esta enfermedad que desde hace varios años es considerada una de las prácticas más eficientes en la reducción de esta infección. (Kassem, 2016).

Los rotavirus que originan el parasitismo intestinal son difíciles de controlar, no solo por su gran difusión, sino por los microbios que provienen principalmente de las heces humanas, que llegan a la boca del niño o niña, por transmisión fecal - oral. Además, de otros factores relacionados con la transmisión tales como; la pobre diversos factores que intervienen en su cadena de propagación. Los mismos mantienen altas tasas de prevalencia en niños menores de tres años, siendo los más comunes las ascariosis, tricocefalosis, giardiosis, y amebiosis, las cuales se encuentran entre las diez infecciones más comunes en el mundo. (Kassem, 2016).

\section{Factores de Riesgo que inciden en las Diarreas}

Para lograr la identificación de factores de riesgo que influyen en la aparición de la diarrea que perjudican la salud de los niños lactantes o menores de cinco años, se requiere de la 


\section{Morbimortalidad producida por enfermedad diarreica}

Vol. 3, núm. 4., (2019)

Jessica Karina Borja Arias; Karol Natalie Galarza Ávila; Luis Javier Álvarez Moyon; Andrea del Consuelo Torres Guzmán

valoración del médico tratante, la cual permite la correcta interpretación, agrupamiento y análisis de los datos, es decir, representa una compleja actividad cognoscitiva que requiere de conocimientos obtenidos a partir de la teoría, experiencia personal y otras fuentes. (Brown, 2015)

Los factores de riesgos representan la medición de la probabilidad de que ocurra un daño, se infiere que el enfoque de riesgo contribuye a la detección de los grupos más expuestos y vulnerables, de allí establecen lo siguiente: un individuo se encuentra en una situación de riesgo cuando en el confluyen factores de distintas índole: sociales, familiares y económicos. Lo referido lleva a establecer que, los factores predisponentes en las diarreas, son circunstancias o variables asociadas con una mayor probabilidad que se produzca la enfermedad donde el problema a resolver es precisar estos factores su relación y si es posible el control de dicho problema de manera aislada o conjunta.

Entiéndase con esto que, la salud de los individuos va a estar influenciada, más que cualquier otro factor por las condiciones del medio ambiente que rodea al individuo, dichas condiciones si no son las adecuadas la morbilidad y mortalidad de muchas enfermedades será elevada, lo que lleva a entender que el ambiente puede actuar dañinamente transmitiendo agentes infecciosos a través del agua, suelos o alimentos.

De allí que, las precarias condiciones de vida expresada en la carencias de servicios de saneamiento básico, inadecuada disposición de aguas negras y excretas, deficiente o ausente suministro de agua potable e insuficiente recolección y disposición final de los residuos sólidos constituyen un riesgo para la salud. De allí que, la valoración acerca del entorno inmediato se considera una necesidad fundamental en la vida de la persona y está íntimamente unida al 


\section{Morbimortalidad producida por enfermedad diarreica}

Vol. 3, núm. 4., (2019)

Jessica Karina Borja Arias; Karol Natalie Galarza Ávila; Luis Javier Álvarez Moyon; Andrea del Consuelo Torres Guzmán

concepto de salud el cual es concebido como el equilibrio entre el hombre y el medio, explica la influencia de los factores en la aparición de las enfermedades. (Grant, 2015)

En otras palabras, es importante señalar que el Síndrome Diarreico Agudo puede presentarse en las personas y niños debido a la presencia de diferentes factores referidos tanto al él, al adulto a cargo, a su alimentación o al ambiente que lo rodea. La diarrea aguda trae consecuencias muy importantes en la salud de los infantes, entre las cuales se encuentran la desnutrición, deshidratación y la disminución en el crecimiento e infecciones, pudiendo llegar a ser letales, lo que lleva a establecer la necesidad de conocer y prevenir los posibles focos de contaminación que estén a su alcance. (Grant, 2015)

Entre las causas más frecuentes se señalan la mala manipulación y contaminación de los alimentos y condiciones higiénico-sanitarias deficientes. Otros factores que incrementan el riesgo de diarrea son el bajo peso al nacer y algunas enfermedades de base o intercurrentes como las enfermedades inmunosupresoras, entre otras. (Grant, 2015). En virtud de esto, se debe destacar que el acceso al agua salubre, buenas prácticas higiénicas y el lavado de las manos con jabón, representan las normas o medidas preventivas a seguir para reducir la incidencia de las enfermedades diarreicas en más de un 40\%, convirtiéndose así en una de las intervenciones más costo-eficaces para reducir las muertes infantiles y de adultos por esta enfermedad desatendida.

Conforme a lo señalado se debe expresar que, los factores de riesgo para contraer, prolongar o complicar la enfermedad diarreica pueden provenir de distintos lugares como el ambiente que se desarrolla la familia en torno a la fuente de agua que tenga el hogar y la administración de alimentos contaminados, un inadecuado manejo de excretas, hacinamiento, 


\section{Morbimortalidad producida por enfermedad diarreica}

Vol. 3, núm. 4., (2019)

Jessica Karina Borja Arias; Karol Natalie Galarza Ávila; Luis Javier Álvarez Moyon; Andrea del Consuelo Torres Guzmán

familiares con enfermedad diarreica, viajes, presencia de animales, condiciones higiénicas deficientes, mal medio social, bajo nivel de comprensión materna o madre adolescente. (Grant, 2015)

Lo referido anteriormente permite señalar que, entre los factores de riesgo de contaminación más específicos se incluyen: fracaso de la alimentación con leche materna exclusiva durante el primer año de vida, alimentación con biberones los cuales se contaminan con microorganismos si no se esterilizan o consumen inmediatamente, alimentos que permanecen a temperatura ambiente y están expuestos a diferentes vectores, uso de aguas contaminadas, falta de lavado de manos después de la defecación o previo a la preparación de alimentos y la presencia de vectores e higiene inadecuada en la preparación de comidas del niño. (Grant, 2015)

Según la Organización Mundial de la Salud, (OMS 2017), la diarrea está relacionada con factores sociales y un acceso inadecuado al agua potable, lo que constituye la segunda causa de muerte en el mundo. Con igual importancia, se establece el factor económico, el cual va influenciado por "la situación social que vive el país determinando la aparición y desarrollo de la pobreza con una caída de los ingresos familiares y deterioro de los sectores sociales" (

Asimismo, la inadecuada conservación de los alimentos constituyen factores de riesgo para la salud y en donde los niños representan un grupo vulnerable. Dentro de este contexto, se puede evidenciar que la salud está condicionada por la expresión concreta, dinámica, evolutiva y real de la situación avance estructural y económico de la sociedad, en donde su mayor exponente 


\section{Morbimortalidad producida por enfermedad diarreica}

Vol. 3, núm. 4., (2019)

Jessica Karina Borja Arias; Karol Natalie Galarza Ávila; Luis Javier Álvarez Moyon; Andrea del Consuelo Torres Guzmán

es la pobreza la cual es responsable del principal factor de mortalidad y causa primera de enfermedad y sufrimiento en el mundo.

\section{Conclusiones.}

La diarrea es una enfermedad que revela una alteración fisiopatológica de una o varias funciones del intestino (secreción, digestión, absorción o motilidad) y que en último término indica un trastorno del transporte intestinal de agua y electrolitos. Asimismo, se establece que esta patología representa un mecanismo de respuesta por parte del organismo frente a un agente agresor, por lo que puede derivar de una diarrea infecciosa, cuando es causada por enteropatógenos como bacterias, virus, hongos, parásitos y no infecciosa, inflamatoria, endocrina, tumoral, medicamentosa o por mal absorción.

Las causas no infecciosas de la diarrea están dadas por una dieta inadecuada (la ingestión de grandes cantidades de alimentos, las fórmulas de leche muy concentradas, etc.), por medicamentos (preparados de hierro, antibióticos), sustancias que actúan como laxantes, por alergias transitorias a las proteínas de la dieta, contaminación del agua por agentes químicos (arsénico, plomo, mercurio entre otras) o por enfermedades endocrino metabólicas.

El diagnóstico etiológico de las diarreas agudas es complejo; esto, debido a que sus causas, especialmente en niños y ancianos pueden ser diversas, siendo la principal de ellas los agentes infecciosos, y posteriormente el aislamiento de enteropatógenos, encontrándose entre ellos, principalmente bacterias en $42 \%$ - 50\%, rotavirus $24,1 \%$ y parásitos $6,5 \%$; todos estos transmitidos por causas diversas. 


\section{Morbimortalidad producida por enfermedad diarreica}

Vol. 3, núm. 4., (2019)

Jessica Karina Borja Arias; Karol Natalie Galarza Ávila; Luis Javier Álvarez Moyon; Andrea del

Consuelo Torres Guzmán

De manera puntual, la etiología de la diarrea aguda infecciosa, incluye bacterias, parásitos y virus, la misma varía según la edad y el área geográfica; de allí, que se estima que el 90\% de las gastroenteritis en niños menores de 3 años son de etiología viral, entre estos los virus más frecuentemente implicados son Rotavirus, Adenovirus, Norovirus, Astrovirus y Sapovirus; señálese también que los Adenovirus representan el segundo agente causal de gastroenteritis agudas después del Rotavirus, y constituye entre el 5 - 20\% de los casos de diarrea en niños hospitalizados.

Por lo tanto, se puede decir que existe un número considerable de elementos infecciosos que conducen a cuadros diarreicos agudos, lo que lleva a considerar la importancia que tiene el comportamiento humano en la transmisión de las infecciones intestinales por parásitos, por lo tanto el éxito de las medidas de control que se implementen dependerá en gran medida de la modificación que se obtenga de los hábitos asumidos por las poblaciones en el sentido de promover la salud y no contribuir a deteriorarla.

\section{Bibliografía.}

Arias, F. (2010). Paradigmas de la Investigación Científica. España: Luces.

Brown, D. (2015). Nutritiond management. Review: The Journal Medic Intensive, 11.

Grant, P. (2015). Factores que inciden en la Diarrea Aguda. Revista de Salud Intensiva de la Habana Cuba, 33.

Kassem, B. (2016). Effect of antibiatics ondurationof diarrhoea and speed of rehydration. Review: The Journal Medic, 22-23.

Mota, A. (2016). Procedimientos médiws para la Diarrea Aguda. Revista de Salud de la Universidad de México, 33. 


\section{Morbimortalidad producida por enfermedad diarreica}

Vol. 3, núm. 4., (2019)

Jessica Karina Borja Arias; Karol Natalie Galarza Ávila; Luis Javier Álvarez Moyon; Andrea del Consuelo Torres Guzmán

Ortiz, H. (2017). Hidratación oral en Diarreas. UNICEF, Ed Med Hosp Infant Mex. Méxiw, D.F.,, $15-17$.

Pereira, F. (2016). Tratamiento para diarreas Agudas. Review: Declaracion conjunta OMS/UMCEF., 11-23.

$$
\text { (9) }(1)(9
$$

RECONOCIMIENTO-NOCOMERCIAL-COMPARTIRIGUAL

CC BY-NC-SA

ESTA LICENCIA PERMITE A OTROS ENTREMEZCLAR, AJUSTAR Y CONSTRUIR A PARTIR DE SU OBRA CON FINES NO COMERCIALES, SIEMPRE Y CUANDO LE RECONOZCAN LA AUTORÍA Y SUS NUEVAS CREACIONES ESTÉN BAJO UNA LICENCIA CON LOS MISMOS TÉRMINOS. 